\title{
Children with Metopic Ridge
}

\author{
Tufan HICDONMEZ \\ Dr. Lutfi Kirdar Education and Research Hospital, Department of Neurosurgery, Istanbul, Turkey
}

\section{ABSTRACT}

AIM: The premature closure of the metopic suture results in metopic synostosis, also known as trigonocephaly. However, there is a group of children who have only a frontal metopic ridge, obvious with inspection and fingertip palpation, without the clinical features of trigonocephaly. This study aims to report a group of children with metopic ridge with a special emphasis on the definition and the diagnostic features.

MATERIAL and METHODS: Thirty-eight children with a diagnosis of metopic ridge were followed up with clinical examinations and photographs in the pediatric neurosurgery outpatient clinic between January 2010 and November 2015.

RESULTS: Children were between 3 and 30 (mean=14) months of age at diagnosis. Twenty-five $(65.8 \%)$ of the children were boys and $13(34.2 \%)$ were girls. A midline metopic ridge without fronto-orbital trigonocephalic deformity was the only diagnostic criterion. The parents' concern about the metopic deformity at initial diagnosis was a common feature in every case. Seven (18.4\%) of the children had a sibling with either metopic ridge $(n=4)$ or trigonocephaly $(n=3)$. None of the children had worsened or had received surgery in the follow-up period.

CONCLUSION: The metopic ridge is a pathology of the metopic suture and is a concern for parents in the context of craniosynostosis. Radiological investigation and craniosynostosis surgery are unnecessary in children with a metopic ridge.This clinical entity may be considered the mildest form of metopic synostosis.

KEYWORDS: Craniosynostosis, Trigonocephaly, Metopic suture, Metopic ridge

\section{INTRODUCTION}

$\mathrm{T}$ The metopic suture is the first cranial suture to close, and this can occur as early as three months (10,15-17). Metopic synostosis, also known as trigonocephaly, is a form of craniosynostosis caused by premature fusion of the metopic suture $(1-3,6,7,10-12,15)$. It is characterized by narrow forehead, hypotelorism, epicanthal folds, biparietal widening, metopic ridge, raised brows and lateral orbital hypoplasia (3). Trigonocephaly can be mild, moderate and severe $(1,3,6,12,13,15)$.

In clinical practice, besides trigonocephaly, there is a group of children with only a metopic ridge in the frontal midline, starting from the nasofrontal suture and extending toward the anterior fontanel, which is obvious on inspection and with fingertip palpation. Children with a metopic ridge have no characteristic features of either mild or severe trigonocephaly.

Children with clinical features of this simple, non-surgical, and presumably mildest form of the spectrum of metopic synostoses, with no clinical or radiological features of trigonocephaly, are reported in this study with a special emphasis on the definition and the diagnostic features.

\section{MATERIAL and METHODS}

Records of 38 children with metopic ridge from the author's pediatric neurosurgery outpatient clinic from January 2010 to November 2015 were reviewed. Initial and follow-up outpatient examinations were done and clinical photographs were obtained (Figures 1, 2). Radiological assessment with computed tomography (CT) was considered diagnostically unnecessary in this group of children and was not performed. 


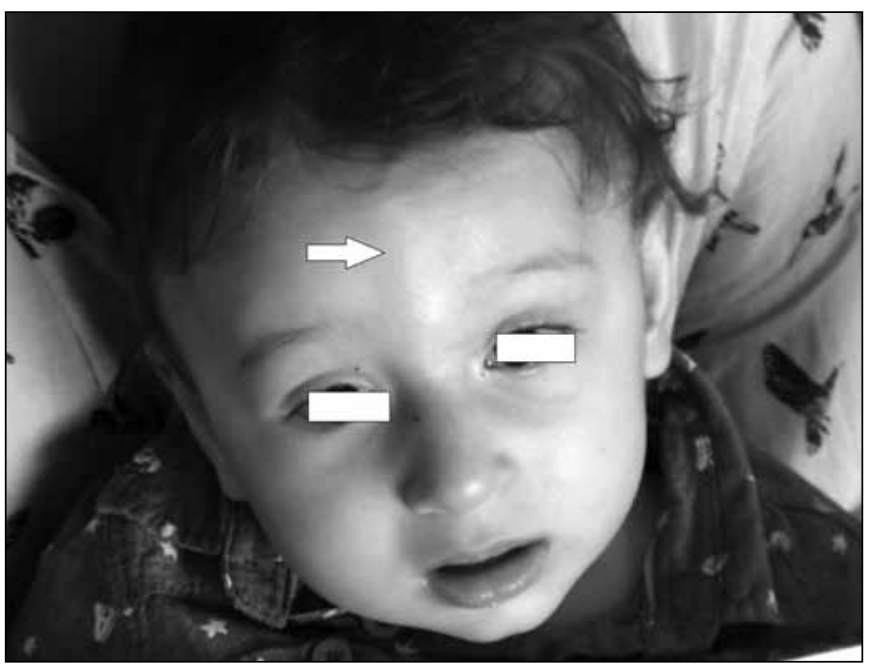

Figure 1: The photograph of a 9-month-old boy with a metopic ridge obvious on inspection (arrow).

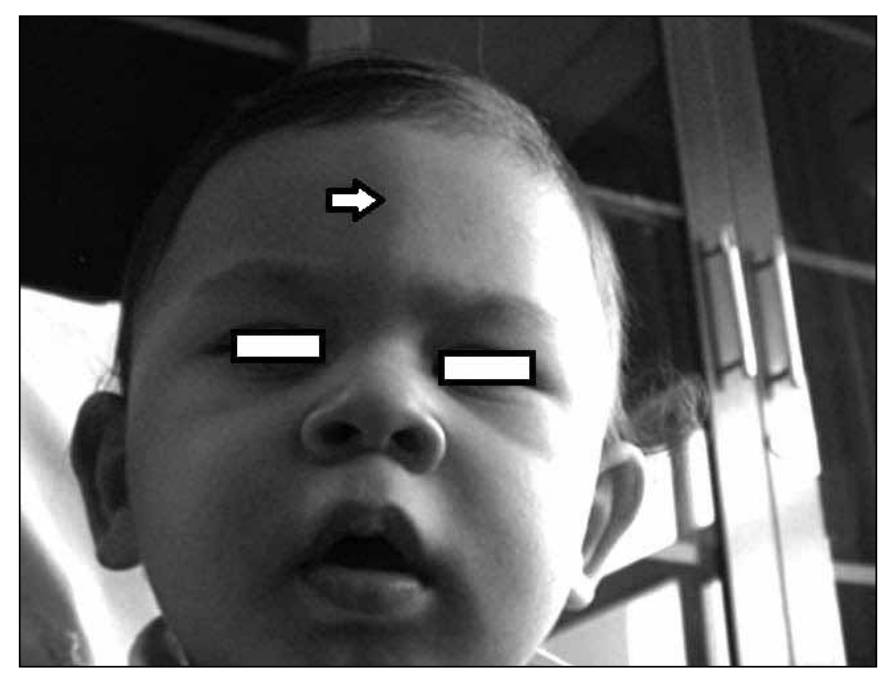

Figure 2: The metopic ridge (arrow) in an 18-month-old boy with no clinical sign of trigonocephaly.

Computed tomography and three-dimensional CT (3D-CT) examinations were evaluated in the study only in referred children who had already had CT and 3D-CT scans done.

\section{- RESULTS}

The study included thirty-eight children between 3 and 30 (mean=14; med=12) months of age at the time of diagnosis. Twenty-five $(65.8 \%)$ of the children were boys; 13 (34.2\%) were girls.

In all children, the only diagnostic criterion was an obvious metopic ridge on inspection and fingertip palpation, with no clinical and radiological features of trigonocephaly (Figures 3 A-D).

In the study group, no radiological assessment was needed for diagnosis, differential diagnosis, or follow-up assessment. At initial examination, $10(26.3 \%)$ children were referred to pediatric neurosurgery with cranial CT and 3D-CT examinations already done.

A total of seven (18.4\%) children with hereditary characteristics had co-incidence of metopic ridge-metopic ridge (two sets of twins) and metopic ridge-trigonocephaly (three children) in siblings.

In all children (100\%), the metopic ridge was a concern for the parents in terms of craniosynostosis and whether the child would worsen and would require surgery for correction.

Twenty-two (57.8\%) children were followed up in the outpatient clinic for 6 to 26 (mean=16.8 \pm 6.67 ) months. Seven $(18.4 \%)$ of the children have been diagnosed within the past 6 months and are excluded from the follow-up data. Another group of $9(23.7 \%)$ children had no follow-up evaluation. None of the children worsened or had surgery in the follow-up period.

\section{- DISCUSSION}

The metopic suture is the first cranial suture to close at the age of three months $(3,10,15-17)$. Weinzweig et al. mentioned that normally only the metopic suture fuses during early childhood and all other sutures fuse much later in life (17). The fusion starts at the nasion, proceeds superiorly in a progressive fashion, and concludes at the anterior fontanel (5). Vu et al. reported that the metopic sutures completely fuse at the age of 9 months (16).

In the three-dimensional sonographic description of normal fetal frontal bones and the metopic suture, Faro et al. reported the presence of a progressive radial bone expansion in the second trimester, and the closure of the metopic suture starting from the glabella and moving toward the anterior fontanel in the third trimester (5). Similarly, in the threedimensional sonographic description of an abnormal metopic suture in second and third trimester fetuses, Chaoui et al. reported pathological changes in the metopic suture of 11 fetuses at 17 to 32 weeks. In fetuses with an abnormal metopic suture, there was an associated midline abnormality such as holoprosencephaly, abnormal corpus callosum, or Dandy-Walker malformation (4).

Premature fusion of the metopic suture results in a form of craniosynostosis, metopic synostosis also known as trigonocephaly, with narrow forehead, hypotelorism, epicanthal folds, biparietal widening, metopic ridge, raised brows, and lateral orbital hypoplasia, and a shortening of the anterior cranial fossa $(1-3,6,7,10-12,15)$. Goodrich and Hall reported that the metopic suture is a common site of sutural synostosis but not at all necessarily site for surgery (6).

According to Hopper et al., metopic ridging is a variant of the normal sutural development of the metopic suture (9). Birgfeld et al. reported that the physiological closure of the metopic suture is often associated with a palpable ridge and is often confused with the ridging associated with premature closure (3). We do not know what makes the metopic suture unique in terms of ridging. The ridging does not occur in other closing sutures, and it does not occur in every child. 
In the relevant literature, there is no conclusive definition of clinical entities of metopic suture pathologies. To our knowledge, Goodrich and Hall's report is the first description of the metopic ridge, a thickened suture. They reported that the metopic synostosis in its mildest form is a familial and inherited facial morphology without clinical significance (6). Additionally Goodrich and Hall stated that metopic synostosis and trigonocephaly are not equivalent clinical entities, referring to metopic synostosis simply as a prominent ridging of the metopic suture without other features of trigonocephaly (6). Metopic synostosis is therefore limited to a mostly nonsurgical metopic ridge, while trigonocephaly describes all surgical forms of metopic synostoses. Moreover, metopic synostosis refers to a suture pathology, but trigonocephaly is a clinical entity (6). Similarly, Aryan et al. reported that in mild forms of metopic synostosis, there is only prominent ridging of the metopic suture, whereas severe cases have frontal narrowing and hypotelorism (1). A palpable metopic ridge was defined by Shimoji et al. as the most important physical sign in a series of mild trigonocephalic patients (13). According to Hopper et al., pathological synostosis must be distinguished from metopic ridging, which is a variant of normal development of the metopic suture with no other features of trigonocephaly (9). Tubbs et al. used the term simple metopic ridging without trigonocephaly, reporting their observations on the possible association with Chiari I malformation (14). Van der Meulen mentioned that the primordia of trigonocephaly can be seen in children with a metopic ridge due to increased bone deposition along the suture, with an unknown etiology and no other clinical or radiological features (15). We are in agreement with van der Meulen because we also think that the metopic ridge is a simple and a mildest form of the spectrum of metopic synostoses or trigonocephaly.
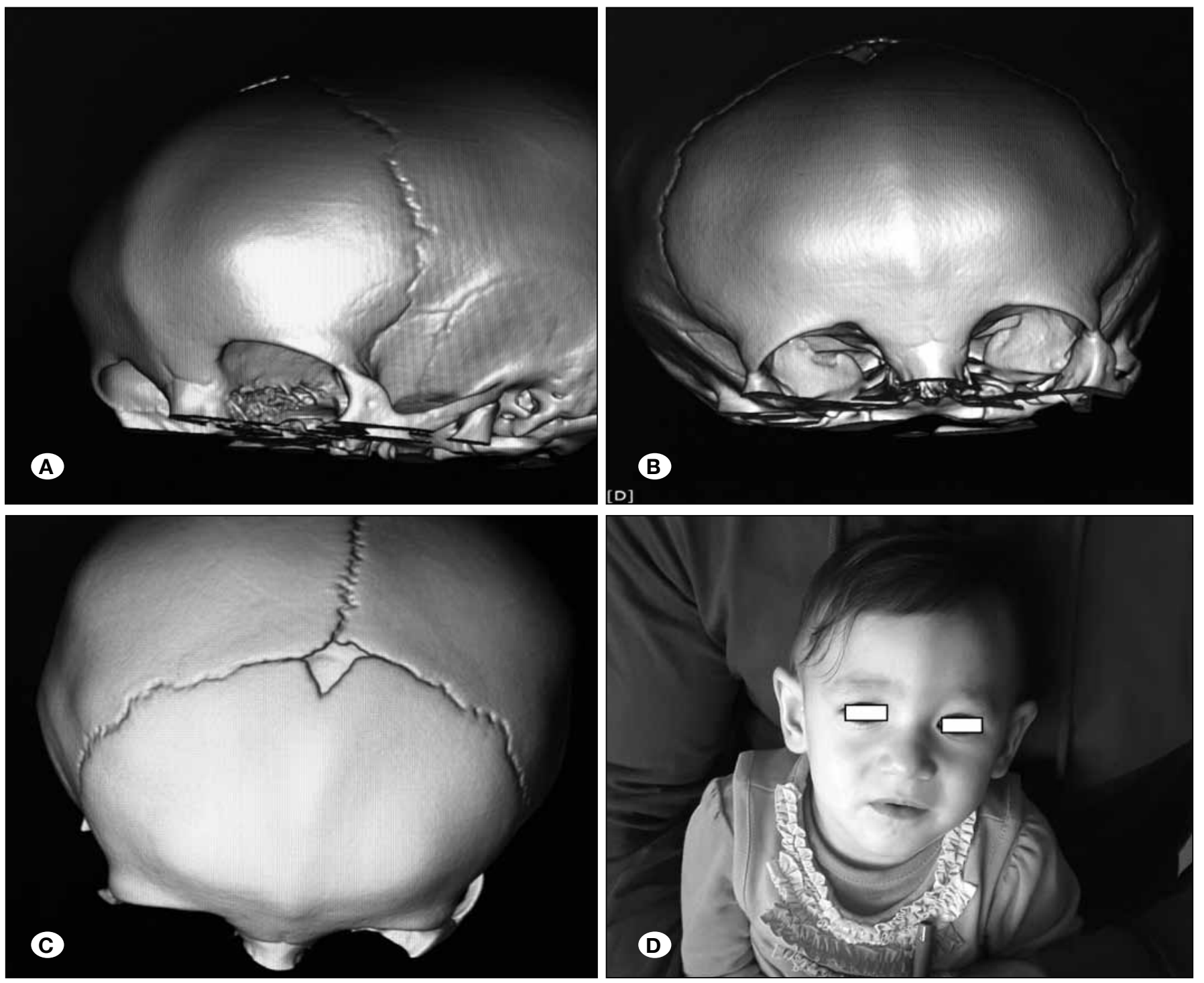

Figure 3: A-C) Three-dimensional computed tomography (3D-CT) scan of a 12-month-old girl with a metopic ridge. Note the prominent midfrontal ridging along the metopic suture between the nasofrontal suture and the anterior fontanel. D) The photograph of the child showing the metopic ridge with no frontal and orbital features of trigonocephaly. 
All children with a metopic ridge in this series had metopic ridging only between the nasofrontal suture and the anterior fontanel. Children with metopic ridging and bilateral orbital deformities resulting in any triangular frontal head shape are diagnosed with metopic synostosis in a mild form, which is clinically a mild trigonocephaly. Children in this group are not considered for surgery and are beyond the scope of this study. The metopic ridge as seen in the children in our study is a very simple pathology resulting in only a very simple bony ridging along the metopic suture. No patient in this study had either triangular head shape or orbital or other characteristic features of trigonocephaly. Oi and Matsumoto described the frontal angle as the angle between two lines drawn bilaterally through the pterion and nasion. A trigonocephaly is classified as being severe, moderate, or mild based on a frontal angle of less than $89^{\circ}$, between $90^{\circ}$ and $95^{\circ}$, and between $96^{\circ}$ and $103^{\circ}$, respectively. Normal children present a frontal angle of $104^{\circ}$ or more (12). In our study, we did not use angle measurements in CT scans because we basically had no rationale to perform an investigation with ionizing radiation in this group of patients with a known diagnosis.

In our study, parents of all children with a metopic ridge were concerned with the deformity in the context of craniosynostosis, and this was the mainstay of the first clinical assessment in the outpatient clinic. The concern was whether or not the child is a craniosynostosis patient and will require surgery for correction of the craniosynostosis. Almost all of the children were referred to pediatric neurosurgery with a likely diagnosis of craniosynostosis, and all of the parents needed to be convinced that the metopic ridge was not actually a surgical pathology and consequently their child would not need surgery.

In our study of metopic ridge, the majority of the children were boys $(65.8 \%)$, suggesting that the metopic ridge is basically a part of metopic synostoses. Heuzé et al. reported that the male to female ratio is about $3: 1$ in metopic synostosis (8). Our results are in agreement with this ratio.

The results of this study suggest the likelihood of hereditary characteristics and co-incidence of metopic ridge-metopic ridge and metopic ridge-trigonocephaly in twins or siblings, as it has been encountered in $18.4 \%$ of cases.

Our present report is, to our knowledge, the second diagnostic assessment of children with metopic ridge. In 2013, Birgfeld et al. reported a study of children with conservative cases of metopic ridge and metopic synostosis that needed surgery, stressing the clinical and radiological differential diagnosis between the two entities. They excluded children with mild trigonocephaly considered too mild for surgery by surgeons and families. To our knowledge, Birgfeld et al.'s study is the first, and it actually consists of a clinical photographic assessment of a group of children to make a differential diagnosis of the metopic ridge and metopic craniosynostosis (3). Birgfeld et al. found that differentiating metopic ridging and metopic suture craniosynostosis (trigonocephaly) is challenging and needs clinical and radiological assessment, such as a CT scan, which can be helpful in identifying trigonocephalic characteristics for diagnosing metopic ridge vs. metopic craniosynostosis (3). However, in our study, we had no clinical difficulties and no need for radiological assessment for the differential diagnosis of metopic ridge and metopic synostosis. It is clinically obvious that the metopic ridge is different from mild trigonocephaly and all forms of metopic synostosis in which there is a metopic prominence that makes the forehead triangular, and other cranio-orbital characteristics of trigonocephaly. Birgfeld et al. reported that children with metopic synostosis present to clinic earlier than children with a metopic ridge (mean 7.7 to 10 months of age) (3). Our study did not compare metopic synostosis and the metopic ridge, but we found that the mean age of children that presented to our clinic with a metopic ridge was 14 months.

\section{- CONCLUSION}

While the metopic ridge is considered a result of the physiological process of metopic suture closure, in some children with no other known clinical or radiological features of trigonocephaly, it is actually a clinical entity in the context of craniosynostosis.

The metopic ridge raises parent's concerns in terms of surgery, similar to those of severe craniosynostoses. The parents need to be convinced that their child does not need surgery for craniosynostosis. More importantly, children with a metopic ridge do not need unnecessary radiological examinations for diagnosis or differential diagnosis.

Presumably, the metopic ridge is the mildest form of metopic synostoses. Further multicenter study of the metopic ridge with a larger number of children and longer term follow-up is required for more detailed diagnostic and clinical evaluation.

\section{- ACKNOWLEDGMENT}

This study is dedicated to the memory of my teacher Professor Umur Kaya (1931-2014), Department of Neurosurgery, Istanbul Faculty of Medicine at Çapa, Istanbul University.

\section{- REFERENCES}

1. Aryan HE, Jandial R, Ozgur BM, Hughes SA, Meltzer HS, Park MS, Levy ML: Surgical correction of metopic synostosis. Childs Nerv Syst 21:392-398, 2005

2. Beckett JS, Chadha P, Persing JA, Steinbacher DM: Classification of trigonocephaly in metopic synostosis. Plast Reconstr Surg 130:442-447, 2012

3. Birgfeld CB, Saltzman BS, Hing AV, Heike CL, Khanna PC, Gruss JS, Hopper RA: Making the diagnosis: Metopic ridge versus metopic craniosynostosis. J Craniofacial Surg 24:178185,2013

4. Chaoui R, Levaillant JM, Benoit B, Faro C, Wegrzyn P, Nicolaides $\mathrm{KH}$ : Three-dimensional sonographic description of abnormal metopic suture in second- and third-trimester fetuses. Ultrasound Obstet Gynecol 26:761-764, 2005

5. Faro C, Benoit B, Wegrzyn P, Chaoui R, Nicolaides KH: Threedimensional sonographic description of the fetal frontal bones and metopic suture. Ultrasound Obstet Gynecol 26:618-621, 2005 
6. Goodrich JT, Hall CD: Surgical management of trigonocephaly. Techniques in Neurosurgery 3:190-197, 1997

7. Hashim PW, Patel A, Chang CC, Beckett JS, Pershing JA: Does an elevated bony ridge along the course of the metopic suture equal metopic synostosis? Implication for management. J Craniofac Surg 25(1): 55-58, 2014

8. Heuze Y, Holmes G, Peter I, Richtsmeier JT, Wang Jabs E: Closing the gap: Genetic and genomic continuum from syndromic to nonsyndromic craniosynostoses. Curr Genet Med Rep 2(3): 135-145, 2014

9. Hopper RA, Grant GA, Ellenbogen RG: Controversies in the management of craniosynostosis. Seminars in Neurosurgery 13:81-96, 2002

10. Karabagli P: Pathology in metopic synostosis. Childs Nerv Syst 29(12): 2165-2170, 2013

11. Lajeunie E, Le Merrer M, Marchac D, Renier D: Syndromal and non-syndromal primary trigonocephaly: Analysis of a series of 237 patients. Am J Med Genet 75: 211-215, 1998

12. Oi S, Matsumoto S: Trigonocephaly (metopic synostosis). Clinical, surgical and anatomical concepts. Childs Nerv Syst 3: 259-265, 1987
13. Shimoji T, Shimabukuro S, Sugama S, Ochiai Y: Mild trigonocephaly with clinical symptoms: Analysis of surgical results in 65 patients. Childs Nerv Syst 18:215-224, 2002

14. Tubbs RS, Elton S, Blount JP, Oakes WJ: Preliminary observations on the association between simple metopic ridging in children without trigonocephaly and the Chiari I malformation. Pediatr Neurosurg 35:136-139, 2001

15. van der Meulen J: Metopic synostosis. Childs Nerv Syst 28: 1359-1367, 2012

16. Vu HL, Panchal J, Parker EE, Levine NS, Francel P: The timing of physiologic closure of the metopic suture: A review of 159 patients using reconstructed 3D CT scans of the craniofacial region. J Craniofacial Surg 12:527-532, 2001

17. Weinzweig J, Kirschner RE, Farley A, Reiss P, Hunter J, Whitaker LA, Bartlett SP: Metopic synostosis: Defining the temporal sequence of normal suture fusion and differentiating it from synostosis on the basis of computed tomography images. Plast Reconstr Surg 112: 1211-1218, 2003 